\title{
Erratum to: Treatment of children with recurrent high grade gliomas with a bevacizumab containing regimen
}

\author{
Chintan Parekh • Rima Jubran • Anat Erdreich-Epstein • \\ Ashok Panigrahy $\cdot$ Stefan Bluml $\cdot$ Jonathan Finlay • \\ Girish Dhall
}

Published online: 26 November 2010

(C) Springer Science+Business Media, LLC. 2010

Erratum to: J Neurooncol

DOI 10.1007/s11060-010-0444-x

In the original publication, the first four column headers are missing in Table 2 . The missing headings should be $\mathrm{P}$ no., Chemotherapy, Surgery and XRT, respectively.

The online version of the original article can be found under doi:10.1007/s11060-010-0444-x.

C. Parekh $(\bowtie)$ - R. Jubran · A. Erdreich-Epstein · J. Finlay · G. Dhall

Division of Pediatric Hematology Oncology, Childrens Hospital Los Angeles, 4650 Sunset Boulevard, MS\# 54, Los Angeles,

CA 90027, USA

e-mail: cparekh@chla.usc.edu

A. Panigrahy $\cdot$ S. Bluml

Department of Radiology, Childrens Hospital Los Angeles,

4650, Sunset Boulevard, MS\# 54, Los Angeles, CA 90027, USA 